\title{
Possible involvement of IL-18 in SLE-dysregulated apoptosis and cytopenia
}

\author{
Mona Hilmy Alrayes* and Mona Mohamed Moursy** \\ Departments of *Clinical Pathology and **General Medicine, Faculty of Medicine for \\ Girls, Alazhar University.
}

\section{Abstract}

Background and objectives: Tissue homeostasis is maintained through a balance between cell proliferation and apoptotic cell death. Dysregulated apoptosis leads to development of autoimmunity like systemic lupus erythematosus (SLE). One of the key biological responses induced by IL-18 is that in combination with IL-12 it stimulates Th1 cell differentiation and involvement in immune responses. Up regulation of Fas ligand in Th1 cells by IL-18 may increase apoptosis of Fas receptor expressing cells that interact with activated Th1 cells. This induction of apoptosis may allow IL-18 to play a role in chronic inflammatory and autoimmune conditions. The aim of this study is to quantify the percentage of apoptotic peripheral blood neutrophils in SLE and to determine the relation with cytopenia. Also the serum level of the proinflammatory cytokine IL-18 is measured in SLE to be correlated with apoptotic neutrophils and other studied parameters. Methods: Neutrophil apoptosis in 30 SLE patients and 15 healthy controls was assessed by flow cytometry using annexin V and 7AAD binding. Serum IL-18 was measured by ELISA and CBC was done by automated cell counter. Results: The percentage of total, early and late apoptotic neutrophils, determined by annexin $\mathrm{V}$ and 7AAD binding, was increased in peripheral blood of SLE patients without corticosteroid therapy (group I, $\mathrm{n}=15)(54.2 \pm 16.3 \%, 36.35 \pm 13.9 \%$ and $17.8 \pm 6.4 \%$ respectively) and also SLE patients with corticosteroid therapy (group II, $n=15)(47.3 \pm$ $28.1 \%, 37.1 \pm 25.6 \%$ and $10.1 \pm 6.6 \%$ respectively) compared with normal controls (group III, $\mathrm{n}=15)(7.24 \pm 3.7 \%, 2.5 \pm 1.5 \%$ and $4.7 \pm 2.9 \%$ respectively). SLE neutrophil apoptosis correlated negatively with WBC $(\mathrm{p}=0.01)$ in group I. Serum IL-18 was significantly elevated in SLE patients with renal complication within group I when compared with SLE patients without renal complication within the same group $(p=0.01)$ and correlated positively with SLE disease activity index (SLEDAI) $(\mathrm{p}=0.001)$. In group II; IL-18 revealed significant negative correlation with \% of both total and early apoptotic neutrophils $(\mathrm{p}=0.02)$ and highly significant negative correlation with absolute lymphocytes $(p<0.0001)$. Conclusion: Increased circulating apoptotic neutrophils in SLE patients may be a pattern of unbalanced process of both apoptosis and clearance of apoptotic material. Neutrophil apoptosis may be a significant cause for SLE associated cytopenia. Effect of IL-18 on neutrophil apoptosis and clearance may be masked or opposed by other undetermined factors in SLE. Corticosteroid therapy may improve neutrophil apoptotic clearance as well as IL-18 inflammatory and antiapoptotic effects in SLE.

\section{Introduction}

The hallmark of autoimmune diseases such as systemic lupus erythematosus (SLE), type 1 diabetes mellitus, dermatomyositis and rheuma toid arthritis is the production of highly

specific autoantibodies that recognize evolutionary conserved molecules. The mechanisms by which these largely intracellular molecules are recognized as foreign are poorly understood (Utz et 
al, 2000). SLE is an autoimmune rheumatic disease characterized by diverse clinical features and presence of auto antibodies in the serum. The path ogenesis remains unknown but exposure to an environmental trigger, in associ ation with a defined genetic backgro und, may lead to profound changes in the immune system. There is increasing evidence that these changes include defective phagocytosis mechanism (Herrmann et al, 1998) and increased apoptotic leukocytes (Perniok et al, 1998).

Apoptosis (programmed cell death), is a process that leads to the ordered destruction of cells, avoiding the release of intracellular contents into the extra cellular microenvironment, where they have a powerful inflamm atory effect (Nakamura et al, 1998). Apoptosis is required to ensure that the rate of cell division is balanced by the rate of cell death in multicellular orga nisms. Dysregulation of apoptosis is associated with the pathogenesis of a wide array of diseases: cancer, neurodeg -eneration, autoimmunity, heart disease and others (Lorenz et al, 2000).

The morphological changes of apoptosis are defined and include contra -ction of chromatin with nuclear and cytoplasmic budding occurring to form membrane bound fragments or apop totic bodies. The auto antigens of hum an SLE, (Ro, La, dsDNA, RNP, ect) are exposed on the surface of apoptotic cells. Therefore, increased apoptotic cells could contribute to excess auto antigens in SLE (Utz and Anderson, 1998).

Early during the process of apoptosis leukocytes lose their phosp holipid membrane asymmetry that leads to externalization of phosphatidylserine (Ps). This membrane change is one of the mechanisms by which phagocytic cells identify apoptotic cells.
Experimental evidence indicates that membrane asymmetry detected by annexin $\mathrm{V}$ is a very early and specific phenomenon during apoptosis, occur ing before the typical morphological changes are apparent. Ps can be detec ted using annexinV, which is a calcium dependent phospholipid binding protein with high affinity for Ps. When annexin $\mathrm{V}$ is conjugated to fluorochrome such as fluoroscein isothyocyanate (FITS) the number of apoptotic cells can be enum erated by flow cytometry (Courtney et al, 1999).

Evidence is to date accumulating to suggest that the nucleosome, the fundamental unit of chromatin and ubiquitous product of cell apoptosis, plays a key role in the pathogenesis of SLE. Nucleosomes play a central role in the antinuclear antibody response in SLE (Nakamura et al, 1995). The main feature of SLE is the formation of antinuclear antibodies, particularly against double stranded (ds) DNA, but dsDNA is very poorly immunogenic. Recent data suggest that the nucleosome is the principal auto antigen in SLE. DNA is present in the circulation of SLE patients in the form of nucleos omes. In vivo, nucleosomes can only be generated through apoptosis. Nucle osome can bind to the surface of several cell types and mediate the binding of antinucleosome antibodies. Patients with SLE have significantly increased levels of nucleosomes in their sera (Berden, 1997). Some anti-DNA antib odies are actually anti-nucleosome antibodies (such as histones and dsDNA). In patients with SLE, reduced clearance of nucleosomes released from apoptotic cells may induce the formation of anti-nucleosome antibody ies (Mevorach, 1999).

The increased rate of apoptosis in SLE would theoretically increase the chance of leakage of intracellular 
antigens that may either trigger an autoimmune response or participate in the formation of immune complexes. Under normal circumstances, apoptotic cells are engulfed by macrophages in the early phase of apoptotic cell death without inducing inflammation or immune response. Recent studies have shown that the clearance of apoptotic cells by macrophages in patients with SLE is impaired (Amoura et al, 1999). After induction of apoptosis most of the cells become late apoptotic within 12 hours. In vivo apoptotic cells can circulate about 24 hours before nuclear material is exposed to the immune system. Therefore, to avoid an immune response, the body has a 24 hour period to remove dying cells (Maekawa and Yasutomo, 2001).

Healthy people remove apoptotic cells efficiently and those cells will therefore not persist in the circulation for longer than 24 hours. When the clearance of apoptotic material is defect -ive, however, released intracellular apoptotic material can cause an immune responses and autoimmune phenom enon. In SLE 24 hours are probably sufficient for removal of apoptotic material, but the problems will arise when large quantities of apoptotic cells are generated; a fundamental defect in the clearance mechanism will then become the limiting factor (Maekawa and Yasutomo 2001).

Complex networks of cytokines have been shown to regulate T-and Bcell growth, differentiation and effector functions. They can be grouped into the cytokines that are associated with Th1 (e.g. IL-2, IL-12, IFN- $\gamma$, TNF- $\alpha$ and IL-18), which induce cell mediated immunity, and those that are associated with Th2 (e.g. IL-4 and IL-10), which stimulate antibody production (Barcellini et al, 1996). Abnormal Th1 and Th2 cytokine response might be involved in the pathogenesis of SLE. IL-18, formerly called interferon (IFN)$\gamma$-inducing factor, is a proinflammatory cytokine related to the IL-1 family. It plays an important role in the innate immunity and Th1 response to toxic shock and shares functional similarities with IL-12. The primary functions of IL-18 include the induction of IFN- $\gamma$ and TNF- $\alpha$ in T cells and natural killer (NK) cells and up-regulation of Th1 cytokines including IL-2, granulocyte macrophage colony stimulating factor (GM-CSF) and IFN- $\gamma$ (Dinarello, 1999). Also IL-18 enhances Fas ligand expression in NK and cytotoxic $\mathrm{T}$ lymphocytes (Dao et al, 1997). Elevated IL-18 levels have been demonstrated in the urine of nephritic patients (Matsumoto and Kammatsure, 2001), serum of patients with multiple sclera osis, type 1 diabetes mellitus, viral infection, sepsis, allergic asthma and inflammatory rheumatic disease (McInnes et al, 2001).

Lupus associated neutropenia (neutrophil count below $1.8 \times 10^{9} / \mathrm{L}$, in the absence of cytotoxic drugs) has been reported in at least $20 \%$ of SLE patients (Keeling and Isenberg, 1993). SLE associated neutropenia is likely to be multifactorial. Patients with SLE can exhibit diminished granulopoiesis and a hypocellular marrow attributable to myelofibrosis or aplasia. Circulating antineutrophil antibodies occur in SLE but their presence in patients with and without neutropenia suggests that, they are not the most important responsible factor (Rosenthal and Farhi, 1989). Neutrophil apoptosis may be a potential contributing factor in SLE neutropenia; which was evidenced by the suppr ession of neutrophil apoptosis by effective treatment using recombinant GM-CSF and corticosteroids (Cox, 1995). Also apoptosis of neutrophils limits their proinflammatory potential 
(functional impairment) in patients with SLE rendering them to be susceptible to bacterial infection (Majewska et al, 2000).

\section{Subjects and Methods}

The present study was conducted on 30 SLE females who were recruited from the outpatient clinic and rheum atology inpatient ward of Alzahraa University Hospital. Diagnosis of SLE was established according to the 1982 revised American Rheumatism Association criteria (ARA), and disease activity was evaluated by the SLE disease activity index (SLEDAI). They were classified into 2 groups. Group I: consisted of 15 SLE females, their ages ranged from 18-55 years. They were not under corticosteroid therapy. Group II consisted of 15 SLE females under corticosteroid therapy, their ages ranged from 18-53 years. Patients taking cytotoxic drugs were excluded from the study. Group III: consisted of 15 appar ently healthy females, age matched as a control group. Their ages ranged from 20-50 years. All subjects were subjected to complete history taking \& clinical examination and the following labor atory investigations: complete blood count (CBC) was done by automated cell counter model Cell Tac auto $\alpha$, erythrocyte sedimentation rate (ESR) by
Wester green method. Flow cytometric analyses were perfor -med on Becton Dickinson FACS caliber using BD biosciences kits. Neutrophils were identified on the bases of light scatter properties. Five thousand neutrophils were analyzed per sample. Dual colour histograms were analyzed for annexinV-PE labeled and 7-AAD labeled cells. The percentage of early apoptotic neutrophils (stained with annexin $\mathrm{V}$ only), the percentage of late apoptotic cells (stained with both annexin $\mathrm{V}$ and 7AAD) and the perce ntage of necrotic cells (stained with 7AAD only) were determined. Serum IL-18 was measured by ELISA using human IL-18 ELISA kit of Medical \& Biological laboratories co Ltd, Nagoya, Japan.

\section{Statistical analysis}

The statistical significance of the results was determined using Student's t test for unpaired samples. Pearson correl ation coefficients were used to study the relations between neutrophil apoptosis and IL-18 measures and other studied parameters. A probability $(\mathrm{P})$ value < 0.05 was considered as indicating signifycant difference.

\section{Results}

Table (1): shows comparison between group I and group III as regard all studied parameters.

\begin{tabular}{|c|c|c|c|c|c|}
\hline Parameter & $\begin{array}{l}\text { Group I } \\
\text { Mean } \pm \\
(n=15)\end{array}$ & $\begin{array}{l}\text { Group III } \\
\text { Mean } \pm \text { SD } \\
(n=15)\end{array}$ & $\mathbf{t}$ & $\mathbf{P}$ & $\begin{array}{l}\text { Significa } \\
\text { nce }\end{array}$ \\
\hline $\mathrm{X} 10^{9} / \mathrm{L}$ & $5.4 \pm 1.0$ & $7 \pm 1.2$ & 3.7 & $0.001 *$ & HS \\
\hline Absolute neutrophils & $3.3 \pm 0.8$ & $5.0 \pm 0.95$ & 4.9 & $0.001 *$ & HS \\
\hline Absolute lymphocytes & $1.97 \pm 0.7$ & $2.6 \pm 0.7$ & 2.3 & $<0.05 *$ & $\mathrm{~S}$ \\
\hline ESR & $61.0 \pm 19$ & $7.0 \pm 2.0$ & 10.1 & $0.0001 *$ & HS \\
\hline$\%$ of total apoptotic neutrophils & $54.2 \pm 16.3$ & $7.24 \pm 3.7$ & 10.9 & $0.0001 *$ & HS \\
\hline$\%$ of early apoptotic neutrophils & $36.4 \pm 13.9$ & $2.5 \pm 1.5$ & 9.4 & $0.0001 *$ & HS \\
\hline$\%$ of late apoptotic neutrophils & $17.8 \pm 6.4$ & $4.7 \pm 2.9$ & 7.0 & $0.0001 *$ & HS \\
\hline $\mathrm{IL}-18 \quad \mathrm{pg} / \mathrm{ml}$ & $506 \pm 355$ & $245 \pm 148$ & 2.6 & $<0.05 *$ & $\mathrm{~S}$ \\
\hline
\end{tabular}

S: significant HS: highly significant 
There is highly significant elevation of ESR, \% of total apoptotic neutrophils, $\%$ of early apoptotic neutrophils and \% of late apoptotic neutrophils with only significant eleva- tion of IL-18 and high significant reduction of WBC and absolute neutrophils with significant reduction of absolute lymphocytes in group $I$ in comparison with group III.

Table (2): shows comparison between group II and group III as regard all studied parameters.

\begin{tabular}{|c|c|c|c|c|c|}
\hline Parameter & $\begin{array}{l}\text { Group II } \\
\text { Mean } \pm \text { SD } \\
(n=18)\end{array}$ & $\begin{array}{l}\text { Group III } \\
\text { Mean } \pm \text { SD } \\
(n=15)\end{array}$ & $\mathbf{t}$ & $\mathbf{P}$ & $\begin{array}{l}\text { Signific } \\
\text { ance }\end{array}$ \\
\hline $\mathrm{X} 10^{9} / \mathrm{L}$ & $6.8 \pm 2.0$ & $7.0 \pm 1.2$ & 0.2 & 0.8 & NS \\
\hline Absolute neutrophils & $4.7 \pm 2.0$ & $5.0 \pm 1.0$ & 0.6 & 0.5 & NS \\
\hline Absolute lymphocytes & $1.9 \pm 0.7$ & $2.6 \pm 0.7$ & 1.0 & 0.3 & NS \\
\hline ESR & $55.0 \pm 30$ & $7.0 \pm 2.0$ & 7.0 & $0.0001 *$ & HS \\
\hline$\%$ of total apoptotic neutrophils & $47.3 \pm 28.1$ & $7.24 \pm 3.7$ & 5.5 & $0.0001 *$ & HS \\
\hline$\%$ of early apoptotic neutrophils & $37.1 \pm 25.6$ & $2.5 \pm 1.5$ & 5.2 & $0.0001 *$ & HS \\
\hline$\%$ of late apoptotic neutrophils & $10.1 \pm 6.6$ & $4.7 \pm 2.9$ & 2.9 & $0.006 *$ & $\mathrm{HS}$ \\
\hline $\begin{array}{ll}\mathrm{IL}-18 & \mathrm{pg} / \mathrm{ml}\end{array}$ & $345 \pm 331$ & $245 \pm 148$ & 1.1 & 0.3 & $\mathrm{NS}$ \\
\hline
\end{tabular}

HS: highly significant NS: non significant

There are highly significant elevations of ESR, \% of total apoptotic neutrophils, $\%$ of early apoptotic neutrophils and $\%$ of late apoptotic neutrophils in group II in comparison with group III.

Table (3): shows comparison between group I and group II as regard all studied parameters.

\begin{tabular}{|c|c|c|c|c|c|}
\hline Parameter & $\begin{array}{l}\text { Group I } \\
\text { Mean } \pm \text { SD } \\
(n=18)\end{array}$ & $\begin{array}{l}\text { Group II } \\
\text { Mean } \pm \text { SD } \\
(n=15)\end{array}$ & $\mathbf{t}$ & $\mathbf{P}$ & $\begin{array}{l}\text { Significanc } \\
\text { e }\end{array}$ \\
\hline $\mathrm{X} 109 / \mathrm{L}$ & $5.4 \pm 1.0$ & $6.8 \pm 2.0$ & 2.35 & $0.03 *$ & $\mathrm{~S}$ \\
\hline Absolute neutrophils & $3.3 \pm 0.8$ & $4.7 \pm 2.0$ & 2.23 & $0.03 *$ & $S$ \\
\hline Absolute lymphocytes & $1.97 \pm 0.7$ & $1.9 \pm 0.7$ & 0.4 & 0.7 & NS \\
\hline ESR $\mathrm{mm} / 1^{\mathrm{st}} \mathrm{h}$ & $61.0 \pm 19$ & $55.0 \pm 30$ & 1.1 & 0.3 & NS \\
\hline$\%$ of total apoptotic neutrophils & $54.2 \pm 16.3$ & $47.3 \pm 28.1$ & 0.77 & 0.5 & NS \\
\hline$\%$ of early apoptotic neutrophils & $36.4 \pm 13.9$ & $37.1 \pm 25.6$ & 0.9 & 0.9 & NS \\
\hline$\%$ of late apoptotic neutrophils & $17.8 \pm 6.4$ & $10.1 \pm 6.6$ & 3.14 & $0.004 *$ & HS \\
\hline IL-18 $\quad \mathrm{pg} / \mathrm{ml}$ & $506 \pm 355$ & $345 \pm 331$ & 1.3 & 0.2 & N S \\
\hline
\end{tabular}

S: significant HS: highly significant NS: non significant

There is significant elevation of WBC \& absolute neutrophils with highly significant reduction of $\%$ of late apoptotic neutrophils in SLE under treatment (group II) when compared with SLE not under treatment (group I).

Comparison between SLE patients in group I with renal complications $(\mathrm{n}=7)$ and SLE patients in the same group without renal complications $(n=8)$ revealed significant elevation of serum IL-18 $(\mathrm{P}=0.01)$ and increased SLEDAI $(\mathrm{P}=0.04)$ in the renal complicated group. Also IL-18 was correlated positively and significantly with SLEDAI $(\mathrm{r}=0.62 \& \mathrm{p}=0.001)$ in SLE with renal complication subgroup. 
Table (4): shows correlation study between \% of total apoptotic neutrophils and other studied parameters among group I ( $n=15)$.

\begin{tabular}{|c|c|c|c|}
\hline Parameter & $\mathrm{r}$ & $\mathrm{P}$ & $\begin{array}{l}\text { Significan } \\
\text { ce }\end{array}$ \\
\hline SLE disease activity index (SLEDAI) & -0.2 & $>0.05$ & NS \\
\hline $\begin{array}{ll}\text { WBC } & X 10^{9} / \mathrm{L}\end{array}$ & -0.75 & $<0.01 *$ & $\mathrm{~S}$ \\
\hline Absolute neutrophils & -0.4 & $>0.05$ & NS \\
\hline Absolute lymphocytes & -0.1 & $>0.05$ & NS \\
\hline $\mathrm{mm} / 1^{\mathrm{st}} \mathrm{h}$ & -0.1 & $>0.05$ & NS \\
\hline$\%$ of early apoptotic neutrophils & 0.92 & $<0.001 *$ & $\mathrm{HS}$ \\
\hline$\%$ of late apoptotic neutrophils & 0.54 & $>0.05$ & NS \\
\hline IL-18 & 0.1 & $>0.05$ & NS \\
\hline
\end{tabular}

S: significant $\quad$ HS: highly significant NS: non significant

This table shows significant negative correlation and high significant positive correlation between $\%$ of total apoptotic neutrophils and both WBC and \% of early apoptotic neutrophils respectively in group I.

Also $\%$ of early apoptotic neutrophils revealed only significant negative correlation with WBC ( $\mathrm{r}=-$ $0.65, \mathrm{p}=0.02$ ) and high significant positive correlation with $\%$ of total apoptotic neutrophils, while \% of late apoptotic neutrophils did not correlate significantly with any of the studied parameters in group I. On the other hand correlation study between IL-18 and the other studied parameters in the same group revealed significant positive correlation with SLEDAI ( $\mathrm{p}=0.004)$ and high significant negative correlation with absolute lymphocytes $(\mathrm{p}<0.0001)$.

Table (5): shows correlation study between \% of total apoptotic neutrophils and other studied parameters among group II $(\mathbf{n}=15)$.

\begin{tabular}{|c|c|c|c|}
\hline Parameter & $\mathbf{r}$ & $\mathbf{P}$ & $\begin{array}{l}\text { Significan } \\
\text { ce }\end{array}$ \\
\hline SLE disease activity index (SLEDAI) & -0.2 & $>0.05$ & NS \\
\hline $\begin{array}{ll}\text { WBC } & \mathrm{X} 10^{9} / \mathrm{L}\end{array}$ & -0.01 & $>0.05$ & NS \\
\hline Absolute neutrophils & 0.13 & $>0.05$ & NS \\
\hline Absolute lymphocytes & -0.37 & $>0.05$ & NS \\
\hline $\mathrm{mm} / 1^{\mathrm{st}} \mathrm{h}$ & -0.1 & $>0.05$ & NS \\
\hline$\%$ of early apoptotic neutrophils & 0.97 & $<0.001 *$ & HS \\
\hline$\%$ of late apoptotic neutrophils & 0.48 & $<0.05^{*}$ & $\mathrm{~S}$ \\
\hline IL-18 & -0.54 & $0.02 *$ & $\mathrm{~S}$ \\
\hline
\end{tabular}

S: significant HS: highly significant NS: non significant

This table shows significant positive correlation between $\%$ of total apoptotic neutrophils and both \% of early and \% of late apoptotic neutro phils, while a significant negative correlation with IL-18 was obtained.

Also $\%$ of early apoptotic neutrophils showed significant negative correlation with IL-18 ( $\mathrm{r}=-0.54, \mathrm{p}=0.02)$ in group II. Correlation study between IL-18 and other studied parameters in the same group did not reveal significant data.

In group III (control) the \% of total apoptotic neutrophils is positively correlated with $\%$ of both early and late apoptotic neutrophils $(\mathrm{p}<0.05)$ and showed non significant negative 
correlations with absolute neutrophils and IL-18 but are difficult to ignore $(\mathrm{p}=0.05)$. Also IL-18 showed significant negative correlation with $\%$ of late apoptotic neutrophils $(\mathrm{p}<0.05)$, these data indicate that IL-18 under normal

$$
\text { 圈 Group I } \square \text { Group II } \square \text { Group III }
$$

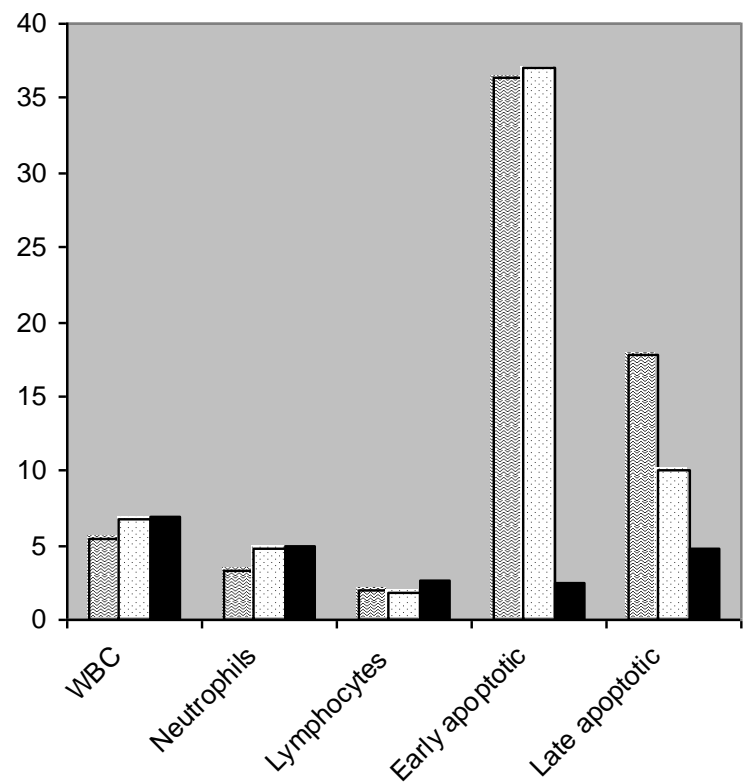

Fig (1): mean values of WBC, neutrophils,

Lymphocytes, \% of early apoptotic neutrophil

and $\%$ of late apoptotic neutrophils in the three studied groups.

\section{Discussion}

Autoantibodies present in the serum of patients with a variety of inflammatory diseases including SLE have proven useful as diagnostic mark ers and as probes to elucidate bioche mical and signaling pathways. The mechanisms governing the generation of autoantibodies remain elusive, const ituting a critical missing link in the conditions may act as antiapoptotic cytokine and may also have effect on clearance of apoptotic neutrophils that may be masked or opposed in SLE patients and improved by corticosteroid therapy.
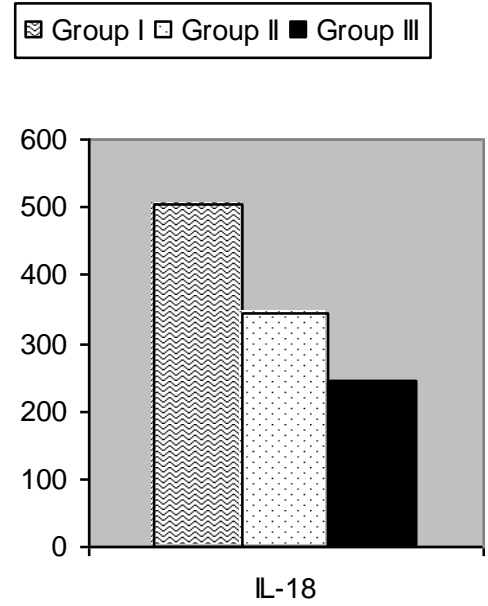

Fig (2): mean values of serum IL-18 in the three studied groups. understanding of rheumatologic illness (Utz et al, 2000).

Apoptosis is a morphologically and biochemically defined form of cell death that plays a significant role in the deletion of autoreactive lymphocytes. Role of apoptosis in bypassing tolerance to intra cellular autoantigens was first demonstrated by Le Feber et al, 1984. The autoantigens were shown to cluster 
in two discrete cell surfaces "membrane blebs". The larger blebs (called apopt otic bodies) contained predominantly Ro, La, snRNPs, and nucleosomal DNA [anti-DNA antibodies are intimately associated with SLE, and their presence has both diagnostic and prognostic significance (von Muhlen and Tan, 1995)]. The smaller structures were recognized by autoantibodies specific for endoplasmic reticulum components, as well as Ro and ribosomal compo nents (Casciola-Rosen et al, 1994). The cells are further modified by the incre ased external cell surface expression of phosphatidylserine (PS) which can bind to annexin $\mathrm{V}$ in the presence of calcium (Casciola-Rosen et al, 1996).

The present study revealed highly significant elevation of ESR, \% of total apoptotic neutrophils, \% of early apoptotic neutrophils and \% of late apoptotic neutrophils $(\mathrm{p}<0.0001)$ with significant elevation of IL-18 $(\mathrm{p}<0.05)$ in SLE patients without treatment (group I) when compared with the control group (III). On the other hand there was highly significant reduction of WBC \& absolute neutrophils $(\mathrm{p}<0.001)$ and significant reduction of absolute lymphocytes $(\mathrm{p}<0.05)$. These data denote increased apoptosis of circulating neut rophils in SLE patients reflected by the increased $\%$ of both total and early apo ptotic neutrophils; thus increased ap optotic process may be a cause of the SLE associated leukopenia and neutro penia. The increased \% of late apoptotic neutrophils may reflect impaired clear ance mechanism. Also lymphopenia may be a result of increased lymphocyte apoptosis which needs further study.

The \% of early apoptotic neutro phils in groups I, II and III were $36.35 \%, 37.1 \%$ and $2.5 \%$ respectively. In a study done by Perniok et al (1998), $\%$ of early apoptotic neutrophils was $13.68 \%$ in SLE cases and $5.62 \%$ in normal controls denoting significant increase of early apoptotic cells in the peripheral blood of SLE patients compared with control. Courtney et al (1999), reported an increased percen tage of apoptotic neutrophils deter mined by annexin $\mathrm{V}$ binding in perip heral blood of SLE patients comp -ared with normal healthy donors $(\mathrm{p}=0.001)$. The plasma membrane phospholipid distribution is altered in the surface blebs of apoptotic cells enabling the binding of annexin $\mathrm{V}$ and generating apoptotic signal. These apoptotic surf ace blebs are major immunogenic particles in patients with SLE (CasciolaRosen et al, 1994). Autoantigens from apoptotic cells may contribute to both activation of autoreactive lymphocytes and formation of immune complex. The general increase of circulating apoptotic cells may indicate an impaired clearance in SLE patients (Mevorach, 1999). Utz et al (2000) reported that cells derived from SLE patients undergo apoptosis spontaneously at a faster rate, and some apoptotic cells, including peripheral blood neutrophils and lymphocytes, circulate at higher levels in the blood of SLE patients. They considered this phenomenon to be a unique characteristic of cells in SLE patients, because other diseases associated with an excess of apoptotic cells (AIDS and systemic vasculities) are generally not associated with high titers of specific autoantibodies (Itescu, 1996).

Group II (SLE patients under corticosteroid therapy) showed high significant elevation of ESR, \% of total apoptotic neutrophils, \% of early apop totic neutrophils and $\%$ of late apoptotic neutrophils $\quad(p<0.0001, \quad p<0.001$, $\mathrm{p}<0.001$ and $\mathrm{p}=0.006$ respectively), while IL-18 and the other parameters did not show significant differences when compared with the control. These 
data demonstrate that corticosteroids could reduce the elevated proinflam matory cytokine IL-18 in SLE patients under treatment.

Comparison between group I and group II revealed significant elevation of WBC \& absolute neutrophils $(p=0.03)$ with high significant reduction of $\%$ of late apoptotic neutrophils $(\mathrm{p}=0.004)$ in group II. Again these results illustrate that corticosteroids have improved the leukopenia and neutropenia in SLE under treatment. The significant reduction in $\%$ of late apoptotic neutrophils in group II may suggest that cortisone therapy has improved the clearance of apoptotic cells. Courtney et al (1999) reported a significant reduction in apoptotic neutrophil count in the high dose corticosteroid SLE group compared with the no-corticosteroid SLE group $(\mathrm{p}=0.02)$. However Weyts et al (1998) reported that cortisole treatment caused an inhibition of neutrophil apoptosis; the effect could be blocked by glucocorticoid receptor blocker, show ing that rescue from apoptosis was receptor mediated.

Comparison between SLE patients in group I with renal complications and SLE patients without renal complic ations in the same group revealed signi ficant elevation of serum IL-18 $(\mathrm{p}=0.01)$ and increased SLEDAI $(\mathrm{p}=0.04)$ in the renal complicated subgroup. Also IL-18 was correlated positively and signif icantly with SLEDAI $(r=0.62, \mathrm{p}=0.001)$ in the renal complicated subgroup. Wong et al (2000) reported high signif icant elevation of plasma IL-18 in SLE patients with renal disease when compared with both SLE without renal disease and normal controls (both $\mathrm{p}<0.01)$. IL-18 was also correlated positively and significantly with disease activity index $(\mathrm{p}<0.0001)$. They suggested that IL-18 plays a crucial role in the inflammatory processes of renal disease in SLE.

SLE patients without corticos teroid treatment in the present study showed significant negative correlation between total WBC and both \% of total and early apoptotic neutrophil denoting that neutrophil apoptosis may be one of the causes of SLE associated cytopenia and neutropenia. Significant negative correlation between IL-18 level and absolute lymphocyte count may suggest the involvement of IL-18 in the process of lymphocyte apoptosis and lymph openia in SLE. On the other hand SLE patients under corticosteroid therapy showed highly significant reduction in $\%$ of late apoptotic neutrophils as well as significant increase in both absolute WBC and neutrophils, beside signify cant negative correlation between IL-18 level and \% of both total and early apoptotic neutrophils denoting a modulatory effect of corticosteroids on neutrophil apoptosis and clearance and involvement of IL-18 in this process.

\section{Conclusion and recommendation}

Elevated percent of both early and late apoptotic neutrophils in SLE patients may be a pattern of unbalanced process of both apoptosis and clearance of apoptotic material. Neutrophil apopt osis may be a significant cause for SLE associated cytopenia. IL-18 is involved in leukocyte apoptosis and clearance, but that may be masked or opposed by undetermined factors in SLE. Corticosteroid therapy has a role on improved clearance of apoptotic neutrophils and modulates IL-18 involvement in neutrophil apoptosis in SLE. These results may help to prepare the stage for development of new therapeutic modalities in rheumatic diseases orientated towards the biological regulation of cell survival. 


\section{References}

1. Amoura Z, Piette IC, Bach JF and Koutouzov $S$ (1999): The key role of nucleosomes in lupus. Arthritis Rheum; 42:833-43.

2. Barcellini W, Rizzardi GP and Borghi MO (1996): In vitro type-1 and type-2 cytokine production in systemic lupus erythematosus: lack of relatio nship with clinical disease activity. Lupus; 5:139-45.

3. Berden JH (1997): Immunology in medical practice. Disseminated lupus erythematosus: disturbed apoptosis? Ned Tijdschr Geneeskd; 141: 1848-54.

4. Casciola- Rosen LA, Anhalt $G$ and Rosen A (1994): Autoantigen targeted in systemic lupus erythematosus are clustered in two populations of surface blebs on cultured keratinocytes. J EXP Med; 179:1317-30.

5. Casciola-Rosen LA, Rosen A, Petri $M$ and Schlissel M (1996): Surface blebs on apoptotic cells are sites of enhanced procoagulant activity: Impli cations for coagulation events and antigenic spread in systemic lupus erythematosus. Proc Natl Acad Sci USA; 93:1624-29.

6. Courtney PA, Crockard AD, Williamson K, Irvine AE, Kennedy RJ and Bell AL (1999): Increased apoptotic peripheral blood neutrophils in systemic lupus erythematosus: relat ions with disease activity, antibodies to double stranded DNA, and neutropenia. Ann Rheum Dis; 58:309-14.

7. Cox G (1995): Glucocorticoid treatment inhibits apoptosis in human neutrophils. J Immunol; 154: 4719-25.

8. Dao T, Ohashi K, Kayano T, Kurimoto $M$ and Okamura $H$ (1997): Interferon $\gamma$-inducing factor, a novel cytokine, enhances Fas ligand-mediated cytotoxicity of murine $\mathrm{T}$ helper cells. Cell Immunol; 173:230-5.

9. Dinarello CA (1999): IL-18: a Th1inducing, proinflammatory cytokine and new member of the IL-1 family. $\mathrm{J}$ Allergy Clin Immunol; 103:11-24.

10. Herrmann M, Voll RE, Zoller OM, Hagenhoffer M, Ponner BB and
Kalden JR (1998): Impaired phagocytosis of apoptotic cell material by monocyte derived macrophages from patients with systemic lupus erythematosus. Arthritis Rheum; 41: 1241-50.

11. Itescu S (1996): Rheumatic aspects of acquired immune deficiency syndrome. Curr Opin Rheumatol; 8:346-53.

12. Keeling DM and Isenberg DA (1993): Hematological manifestations of syst emic lupus erythematosus. Blood Rev; 7: 199-207.

13. Le Feber WP, Norris DA and Ryan SR (1984): Ultraviolet light induces binding of antibodies to selected nuclear antigens on cultured kerati nocytes. J Clin Invest; 74: 1545-51.

14. Lorenz HM, Herrmann M, Winkler T, Gaipl U and kalden JR (2000): Role of apoptosis in autoimmunity. Apoptosis; 5: 443-9.

15. Maekawa Y and Yasutomok (2001): Defective clearance of nucleosomes and systemic lupus erythematosus. Trends Immunol; 22:662-3.

16. Majewska E, Sulowska $Z$ and Bay $Z$ (2000): Spontaneous apoptosis of neutrophils in whole blood and its relation to apoptosis gene proteins. Scand J Immunol; 52:496-501.

17. Matsumoto $\mathbf{K}$ and Kammatsuse $\mathbf{K}$ (2001): Elevated IL-18 levels in the urine of nephritic patients. Nephron; 88: 334-9.

18. McInnes IB, Gracie JA and Lieiv FY (2001): Interleukin-18: a novel cytokine in inflammatory rheumatic disease. Arthritis Rheum; 44:1481-3.

19. Mevorach D (1999): The immune response to apoptotic cells. Ann NY Acad Sci; 887: 191-8.

20. Nakamura N, Kuragaki C, Shidara Y, Yamaji $K$ and Wada Y (1995): Antibody to annexin $\mathrm{V}$ has antiphos pholipid and lupus anticoagulant properties. Am J Hematol; 49:347-48.

21. Nakamura N, Ban T, Yamaji k, Yoneda $Y$ and Wada $Y$ (1998): Localization of the apoptosis inducing activity of lupus anticoagulant in an annexin V-binding antibody subset. J Clin Invest; 101: 1951-59. 
22. Perniok A, Wedekind F, Herrmann $M$, Specker $C$ and Schneider $M$ (1998): High levels of circulating early apoptotic peripheral blood mononuclear cells in SLE. Lupus; 7: 113-18.

23. Rosenthal NS and Farhi DC (1989): Bone marrow findings in connective tissue disease. Am J Clin Pathol; 92:650-4.

24. Utz PA and Anderson P. (1998): Posttsanslational protein modifications, apoptosis and the bypass of tolerance to autoantigens. Arthritis Rheum; 41: 1152-60.

25. Utz PA, Gensler TI and Anderson P (2000): Death, autoantigen modifications and tolerance. Arthritis Res; 2: 101-14.

26. Von Muhlen CA and Tan EM (1995): Autoantibodies in the diagnosis of systemic rheumatic diseases. Semin Arthristis Rheum; 24: 323-58.

27. Weyts F A, Flik G, Verburg-van Kemenade B M (1998): Cortisol inhibits apoptosis in carp neutrophilic granulocytes. Dev Comp Immunol; 22:563-72.

28. Wong CK, Li EK and Lam CWK (2000): Elevation of plasma interleukin 18 concentration is correlated with disease activity in systemic lupus erythematosus. Rheumatol; 39: 107881. 


\section{إحتمال تورط إل - 18 فى سوء نظام موت الخلية المبرمج

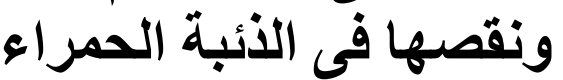

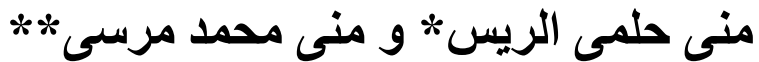

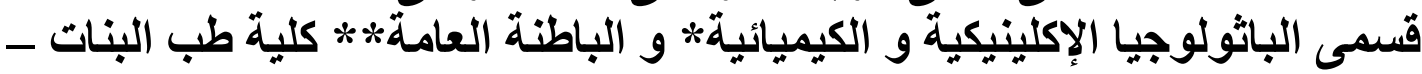

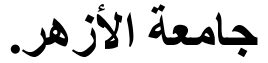

تحتفظ الأنسجة بتوازنها الطبيعى من خلال التوازن بين كل من نمو الخلايـاو موتها

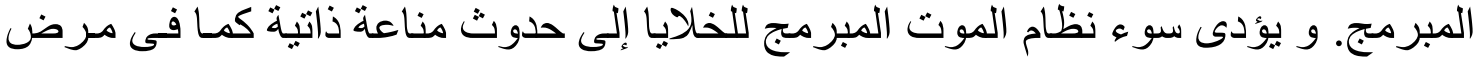

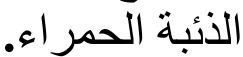
الهـف من البحث:

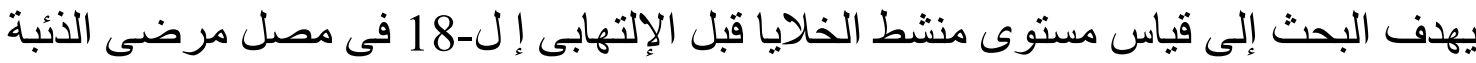

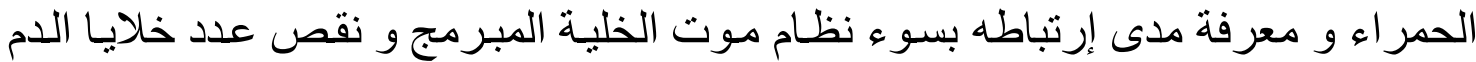

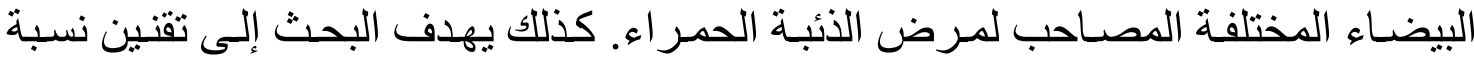

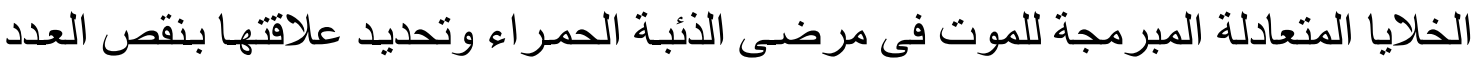
الكلى لأنو اع خلايا الدم البيضاء. البهاء.

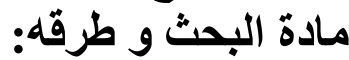

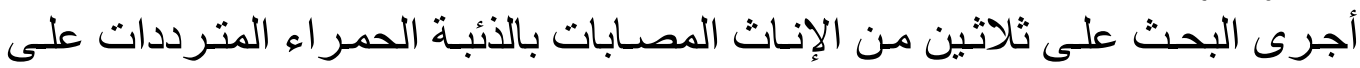

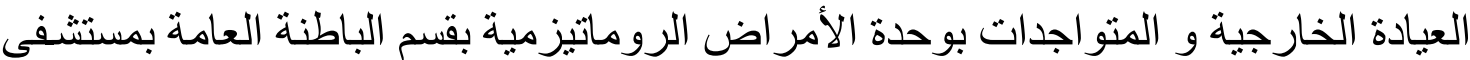

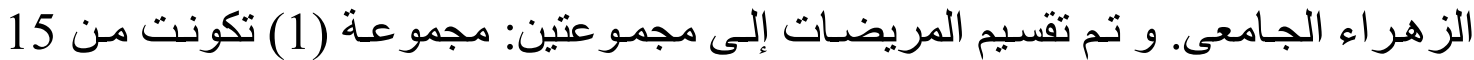

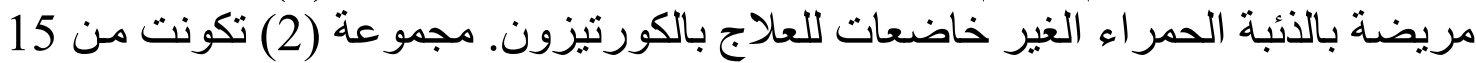

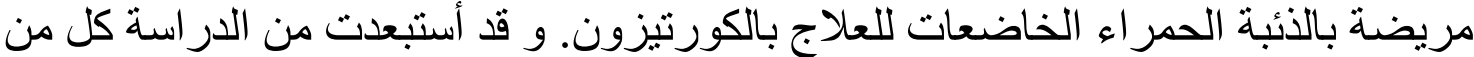

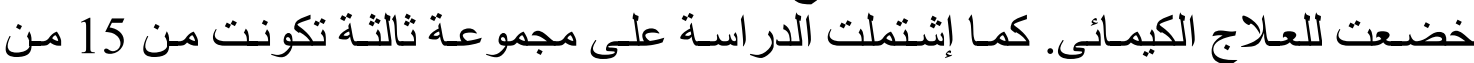

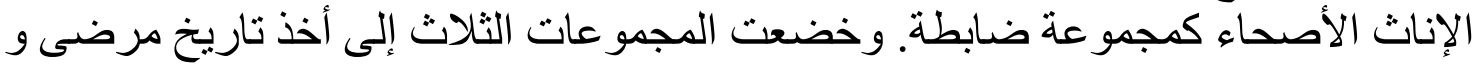

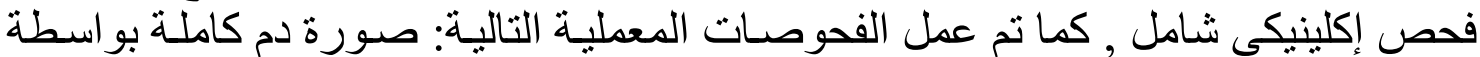

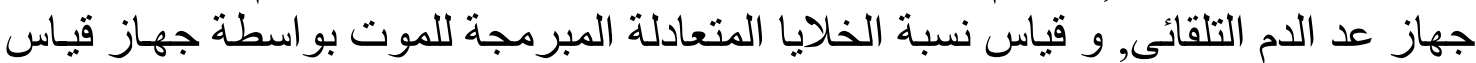

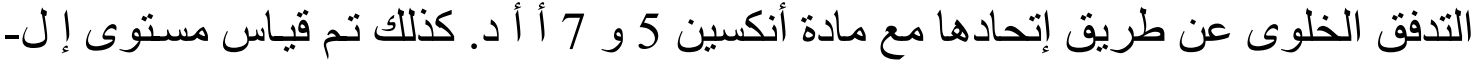

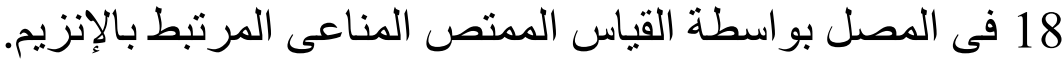
النتائج و التوصيات:

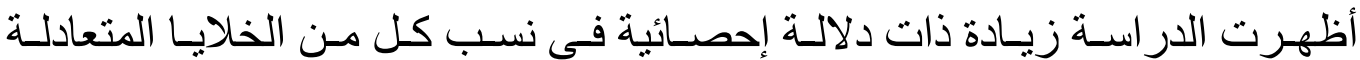

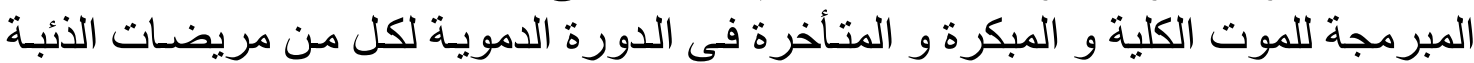

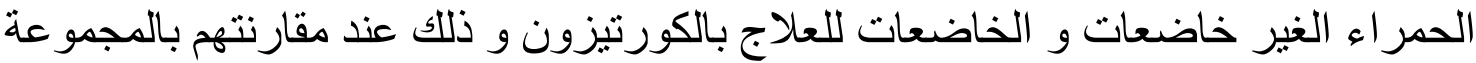

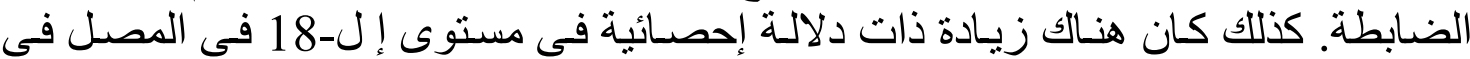

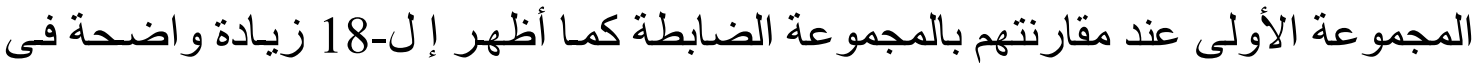

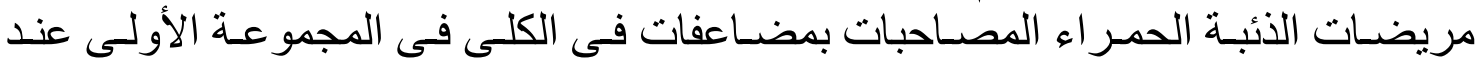

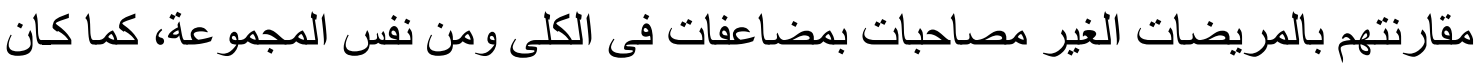

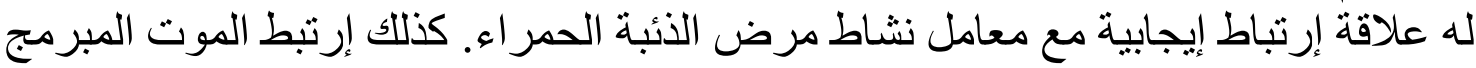




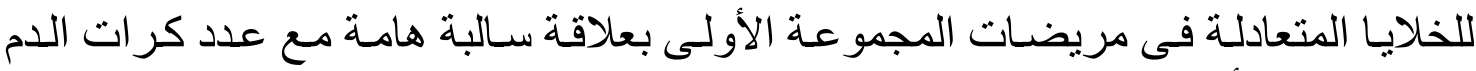

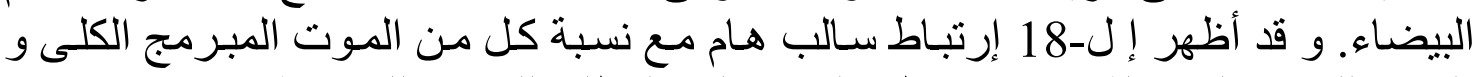
المبكر للخلايا المتعادلة، بينما إرتبط سالبا مع العد المطلق للإل للخلايا الليمفاوية.

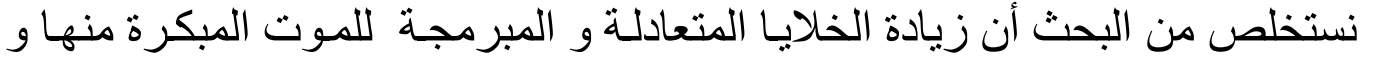

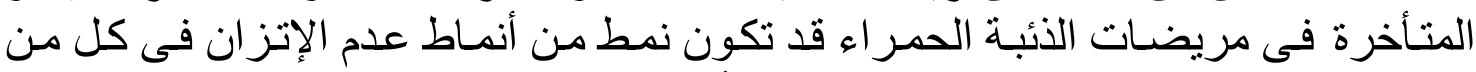

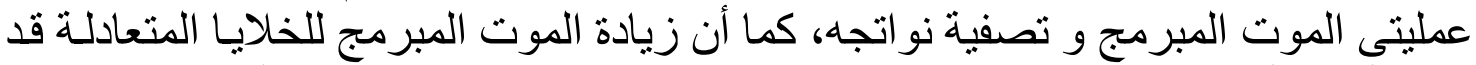

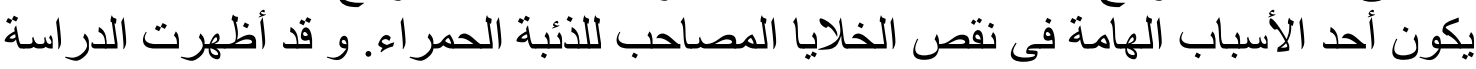

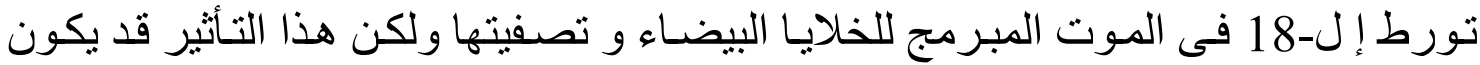

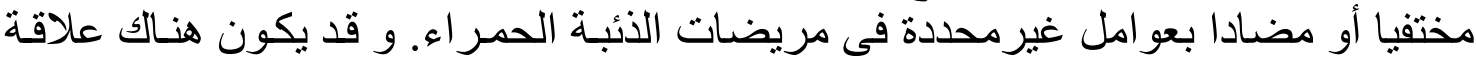

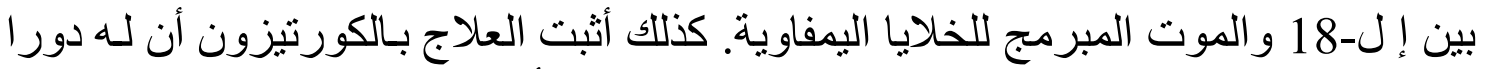

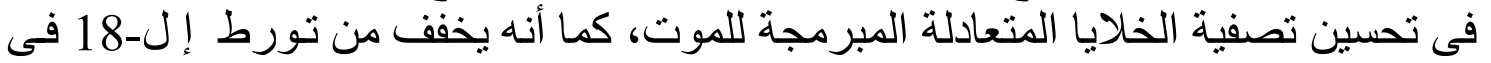

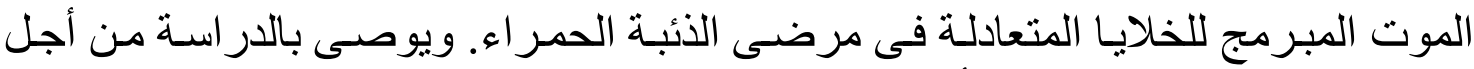

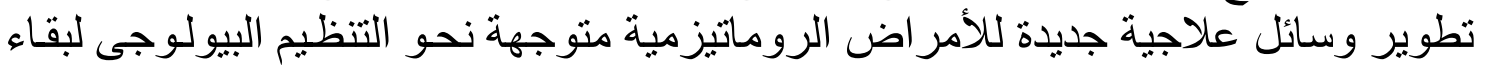

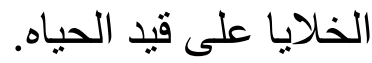

